\title{
Care, Cure and Travel - Towards a Symbiosis of Medical Treatment and Tourism?
}

\author{
By Erik A. Borg ${ }^{*}$ \\ Frank-Michael Kirsch \\ Kjell Ljungbo ${ }^{\dagger}$
}

A growing number of patients seek medical care outside their country of residence. More mobile populations that seek access to information about international medical treatment alternatives have influenced a booming medical tourism industry. The countries engaged in medical tourism are ranging from countries with high cost of medical care like the USA and Japan to medium cost countries, like Singapore and Germany to low cost countries like India and Poland. Engaging in medical tourism by attracting patients internationally involves a process of internationalization of healthcare. Countries have commonly gone through different stages in their approach to medical tourism which has matured the industry. A first stage in the internationalization is encouraging regular travelers to consider treatment options in a destination. A second stage involves the signing of agreements with healthcare systems in countries that can remit patients abroad. A third stage is to develop an integrated organization taking patients all needs before, during and after treatment into consideration. Our study is based on more than 80 in-depth interviews as well as secondary data from countries in Europe, Asia and North America. Much lower medical treatment prices in many Asian and Latin American countries act as driving forces for medical tourism attracting Western medical tourists to seek treatment in those countries.

Keywords: healthcare, internationalization, medical tourism, patient mobility

\section{Introduction}

"The patient in focus" - this phrase can be heard constantly these days. But does the patient really feel being in focus, when often left alone by stressed nurses or a doctor, who communicates more with a computer than face to face with patients?

National health systems try to find affordable solutions to the problem of there being too little time for patients. Today, this is as much a problem for systems with strong private elements as it is for overburdened publicly-funded ones. Cross-border knowledge has become a matter of course, but what about cross-border care?

There is a multitude of motives for patients crossing borders to get medical care. Trust in the treatment and the healthcare professionals is one of the more underestimated reasons. Trust as a motive can be hidden in quality surveys if

\footnotetext{
${ }^{*}$ Professor, Södertörn University, Sweden.

* Professor, Södertörn University, Sweden.

${ }^{\dagger}$ Assistant Professor, Södertörn University, Sweden.
} 
these go to the bottom of things; it can be found as a reason for being dissatisfied with the medical service at home. In an increasingly depersonalized, computerized world, personal contact with human beings who really CARE becomes a priority for patients seeking individual treatment.

This text was originally presented in Greece. Asclepius, the hero and god of medicine in Greek mythology, still represents the medical arts to this day, symbolized by the Rod of Asclepius with the entwined snake. Today it is worth remembering that Asclepius leans in the same way on his walking staff as the free citizen of the Polis. Sufferers were allowed to come and see him for care and cure - or he came to them.

Transnational medical travel can open doors that the patient's home country cannot. We, a Swedish group of researchers with an intercultural background, are focusing on an individual patient's perspective as well as on the economic effects for the national health systems, both in destination and departure countries. Before presenting some of our main thoughts and findings, we have to define medical tourism. Johnston et al. (2010: 12) call it "an increasingly visible and practiced global phenomenon, subject to much conjecture but little regulation or understanding". This is still true, despite the fact that regulation is on the way. On a European level, the EU passed the patient mobility directive (2011/24/EU, 2015). EU citizens can be reimbursed by their social insurance system for planned healthcare obtained in another Member State (CHAFEA, 2014). This regulation has been welcomed, because it aims at making life easier. Other kinds of regulation, like travel bans and walls, are contradictory to the spirit of freedom and mobility. Yesterday's political solutions do not suit the globalized world of today. The current international medical tourism is a part and product of globalization, and its development depends strongly on political wisdom and vision. On a global scale there are about 30 countries strongly engaged in this field, while there are 70 other nations with a few clinics at their disposal, with each attracting international patients (Juszczak, 2017: 36).

\section{Healthcare and Tourism - A Promising Combination}

The term "medical tourism" is an established one in international research literature. Not everyone likes it. During interviews at some of the best U.S. hospitals, we sometimes met medical practitioners who expressed reservations: "We have nothing to do with tourism, only with high quality medical treatment." At the same time, we met hospital representatives who worried about a lack of cultural facilities around the hospital for foreign patients and their fellow travellers. If a patient spends an average of 30 per cent of their time in the clinic, but 70 per cent outside, as we were told at the Mayo Clinic in Rochester regarding cancer patients undergoing repetitive treatment for four to five weeks. Destination offerings like shopping, restaurants, funfairs, as well as art, culture and education, are becoming crucial in the competition for patients (Borg and Ljungbo, 2017). 
It cannot be denied: "Medical tourism is tourism", and, with reference to experiences from Thailand, Malaysia, Singapore, South Korea and Mexico, "the goal of destination country governments is not only to attract patients for health care but to create a multiplier effect from their tourism spending while in the country" (Cohen, 2015: 17).

Others see the combination of "medicine" and "tourism" as a clumsy nexus of "high" and "low". What has saving life got to do with entertainment? A person who needs help does not travel for fun! Such terms as fertility tourism, transplant tourism or stem-cell tourism are grist to the mill of those with arguments of this kind. Incorporated in the English-language research literature and mostly used in a neutral manner, these terms nearly sound cynical in the German, Swedish or Polish languages.

In several interviews in various countries we have found that the main reason for patients to travel to a foreign hospital is the medical quality and outcome of the treatment. So in this sense the critics are right that the medical quality is in focus. But our experience also tells us that there is another factor playing a role here. Medical treatment, and especially advanced medical treatment and care, is a highly regarded area and being a medical doctor is a top status profession, something that is not the case of tourism activities and people working in that field unfortunately often being seen as an ordinary service field. Therefore many doctors would not like to be associated with tourism, it is a matter of pride, prestige and status of their profession and their job.

But what is wrong with a symbiosis of healthcare and tourism? Precisely this symbiosis seems to be medically sensible and economically reasonable. Concerning the medical sense, the sociologist and tourism expert Kerstin Heuwinkel illustrated it at one of the conferences on medical tourism at the University College of Bonn-Rhine-Sieg. Emotionally charged conditions such as illness, holidays and recreation generate an area of tension, where the production of positive energy is possible, but cannot be taken for granted. Whilst illness is often accompanied by fears and uncertainties, holidays and recreation have positive connotations (Heuwinkel, 2009).

The combination of both - healthcare and tourism - promises a story of success, whose end is far from being seen today. If there is a political intent and an active defence of risks, medical tourism can help to break with the decrepit structures of national health systems. Medical tourism is able to keep medical professionals and elite researchers in a country and, if necessary, help the medical profession out of an absurd bureaucratic jungle back to its origins: the duties of care and cure.

\section{Medical Tourism and Health Tourism}

We emphasize the difference between medical tourism and health tourism. Medical tourism means a necessary medical treatment, but health tourism includes spa facilities, wellness and beauty care. There is a grey zone, because 
even spa and wellness can provide benefits to clinically sick persons, especially through medical rehabilitation. Beauty care can improve social wellbeing. But the overwhelming majority of people consuming spa, wellness and beauty care are healthy or health-conscious people, not seriously sick patients in need of medical treatment. In making this difference, the overstated numbers of some destination countries burnishing their international images with foreign patients must be viewed with skepticism.

To quote Anglo-American research literature, C. Michael Hall defines medical tourism as "a more generic term that simply refers to foreign travel for the purpose of seeking medical treatment, with or without a holiday or the consumption of tourism services" (Hall, 2011: 7). Patients crossing borders are for him sufficient evidence to call them medical tourists.

There are patient flows comprising the country's own inhabitants too, but they are not part of our research. Scientifically, it is counterproductive, to measure native and foreign patients by the same yardstick. The German expert in cross-border care, Jens Juszczak, recommends to "regard national and international medical tourism separately in all aspects", explaining it with the different motives of choosing a destination, various valuations, other wants and needs as well as the much sharper heterogeneity of international patients (Kirsch and Białk-Wolf, 2016: 9f). Moreover, their special touristic purposes, export receipts and the different treatment costs compared with their departure country have to be considered (Białk-Wolf, 2010, 2014). But a vital question in our - and others' - research are the consequences of a country's cross-border profile for the local inhabitants and patients (Bookman and Bookman, 2007; Johnston et al., 2010; Von Lutterotti, 2010; NaRanong and NaRanong, 2011).

Other than the already named advantages of cross-border care, what more can a patient receive, and what can be healthy effects on financing health care services? Combining a patient's needs and finances is a practicable path for research in three respects. (1) It leads to a patient-focused perspective without opening floodgates to costly demands. (2) It puts the discussion about efforts to develop medical tourism on a realistic ground. (3) It helps to abandon ideology and prejudice, e.g. medical tourism is only for the rich.

\section{Quality on Top}

Medical tourism strengthens the patient's active status in finding the most convincing individual solution to get cured. A number of international studies identify top quality medical care being first in line for patients travelling abroad to get medical treatment (Ehrbeck et al., 2008; Legido-Quigley and McKee, 2010; Glinos et al., 2010). Saving costs can dominate in some national studies, especially those written with focus on the U.S. market and American patients seeking care abroad. But it would be wrong to describe the motives of medical tourists in terms of lower prices being the dominant or, even worse, the one and only incentive to travel. According to Ehrbeck et al. (2008), 40\% of international medical tourists seek the most advanced medical technology, 
$32 \%$ higher quality, and $15 \%$ want to avoid long waiting lists in the departure country. Only between 9 and $13 \%$ of the patients put lower prices at the top.

A similar point of view is shown in the EU. With multiple answers allowed, $71 \%$ of those who see medical travel as an alternative mention the non-availability of the medical service in their country. For $91 \%$ of the Danes and $87 \%$ of the Swedes it is even the main reason for seeking treatment abroad. "Better medical quality" is mentioned by $53 \%$, especially the Dutch $(74 \%)$, the Bulgarians (70\%), Cypriots (66\%) and Danes (66\%). 38\% are looking for a top specialist performing the treatment, led by Sweden (62\%) and followed by Luxembourg (61\%), Austria (59\%) and Czech Republic (54\%). 34\% name "urgent treatment" as a reason. Both Swedes and Dutch dominate here at $67 \%$ each, since waiting times for special treatments can be extremely long in these countries. Cost savings follow with an average of $23 \%$ first at fifth place (European Commission, 2015).

A reason for patient's lower or lack of interest in financial matters related to medical care inside the European Union are the relatively well-functioning insurance solutions. Politically, the EU has taken a leading role in the internationalization process of medical care. I. Glenn Cohen sees diversity which here means the differences between health care systems - as an explanation for the popularity of European cross-border care: "Providers can and do offer a vastly different array of services and technologies from one Member State to another, much more so than between U.S. states, for example. Because patients can move from one kind of system to another in seeking cross-border care, the interactions between these systems for EU medical tourism are potentially quite complex" (Cohen, 2015: 172).

Other problems remain. The EU's patient mobility directive gets much attention and praise, but patients' hope of getting higher-quality medical treatments have not been fulfilled yet in a viable and satisfactory manner. Higher quality is, as we have seen above, the cross-border patient's deepest wish. One of the aims of the mobility directive was to give small and unknown but innovative clinics in Europe a chance of attracting people from other EU countries and bring attention to the clinic's services, and in doing so, first and foremost, offer a higher treatment quality for patients (Bark, 2011). But even to the present day, such clinics could not usually benefit from the patients' stronger mobility. The reasons become obvious in the evaluation report of the Executive Agency for Consumers, Health and Food (CHAFEA, 2014), but also in empirical observations of countries' practices allowing residents to get medical treatment in member states. The dominating reasons for giving permission are lower costs and reducing waiting lists. In the first instance, the responsible authority decides, not the patient. If you as a patient cannot be certain of being reimbursed for incidental expenses and possibly have not received the authorities' written permission in time before your operation, you feel insecure about travelling. Administrative decisions generate economic savings - cheaper care in another EU-country - priority over excellent treatment quality. Well-informed, courageous patients who claim their right can change the situation and put the emphasis on quality. Research combining 
a patient's perspective with economic aspects can be helpful in finding realistic solutions.

On the one hand, there is still a knowledge gap concerning the economic effects of EU patients' treatment in member-states. On the other hand, research explicitly shows global medical tourism's potential of developing healthcare infrastructure in destination countries while reducing waiting periods and costs for residents of departure countries. But the net loss of capital is a problem for the departure countries: "It is only logical to assume that every patient leaving one health care system for another is taking their capital elsewhere. /.../ Revenue gains in destination countries have been associated with revenue losses in medical tourists' home countries" (Johnston et al., 2010: 8).

The economic aspects of patients seeking medical care abroad also has political implications and repercussions. Local politicians lose influence and power over patients and the health system creating forces of inertia to keep the current system. Similar forces could also exist among medical staff, not least doctors, either for ideological reasons focusing on equality across different groups in society disliking that patients pay for their treatment or for practical reasons: Not giving up a convenient situation where the doctor gets patients sent to him/her instead of having to fight for attracting and winning the patients on an open market. An old and familiar structure featuring no international competition being pleasant and predictable for complacent doctors, health administrators and politicians in the health care industry.

The competition for travelling patients can result in better offers and quality of care. Researchers analyze reasons for diverting patient flows from traditional treatment destinations like the U.S.A. to developing countries like Thailand and India and also to Singapore (Burkett, 2007; Whittaker, 2008; (Kangas, 2010; NaRanong and NaRanong, 2011) and to well-established and new destinations in Europe (Beyer and Juszczak, 2014; Juszczak, 2017). The constructive dynamism process, fuelled and driven by patients, is given attention from a global medical marketplace perspective (Johnston et al., 2010; Heung et al., 2010), a risk-analysis point of view (Mason and Wright, 2010; Rogers et al., 2011) or a human rights and social justice perspective (Sobo, 2009; Whittaker 2008). Medical tourism can also be seen as setting a standard of care (Johnston et al., 2010). Horowitz and Rosensweig (2007) and Underwood and Makadon (2010) regard medical tourism as a competitive cure for the problems facing global health, providing "access to quality health care to those who could not otherwise afford it" (Burkett, 2007: 245).

Nearly all leading countries in medical tourism focus on combining medical care with tourist activities. This approach is clearly promising. The worlds' leading destination, South-East Asia, overwhelmingly shows the attractive power of this symbiosis. With this in mind, it is worth studying what countries are missing if both parts - medical care and tourism - do not find each other. Sweden is a prime example. A technically advanced health system with highly qualified specialists and staff on the one hand and an increasingly targeted tourism sector on the other, with the best conditions for tourists' relaxation, restfulness and freedom - as well as a safe and well-functioning 
society with a rich cultural offer in the major cities - are practically predestined for a cooperation. Sweden's abundant supply of tourist resources with many less frequented places for enjoying silence could be of vital importance for international patients, not least for their recreation. But the potential for transnational medical travel is not yet even perceived, let alone exploited (Kirsch, 2015, 2017).

Other countries are more advanced in this regard. A well-known hospital Florida Hospital for children - has a cooperation with Walt Disney and the hospital is located close to Orlando not so far from the Walt Disney World Resort, the second largest amusement park in the world. This enables children and their parents to combine medical treatment with a great touristic amusement park experience (Grant, 2014).

\section{The Internationalization of Healthcare}

The increase in globalization of the world economy and the liberalization of international institutions has had significant impact on the delivery of healthcare (Holden, 2003). While national healthcare is highly influenced by national regulation, the more self-regulated medical profession is increasingly international in nature. Managerialism and performance measures together with evidence-based medicine and clinical guidelines are improving the accountability of professionals and the safety of patients (Kuhlmann and Burau, 2008). The healthcare sector is in a process of internationalization and is subject of a rapid increase in international trade and foreign direct investment (FDI) (Smith, 2004). The rise of FDI in international healthcare is likely to increase the segmentation and fragmentation of the healthcare industry (Outreville, 1998).

International investors are picking and choosing areas of the medical sector to invest in. Some areas are more profitable than others, and investments are focused on the more profitable area. As a result the healthcare sector is becoming more fragmented where some treatments are covered by private hospitals while others are left to the public sectors. Chronical conditions where the costs of treatment is high and treatment results are limited is more likely to be shunned by private investors unless the conditions can be covered by a private or public insurance. However, all chronical patients are not left out as healthcare is internationalized. One group of patients with a chronic condition which is an exception to this are kidney patients with a need for dialysis. Dialysis patients have often a choice between private or public alternatives. There has been substantial foreign direct investments in dialysis clinics over the past couple of decades.

A World Development Report called "Investing in Health", recommended a public-private mix for financing and organizing health systems. The report has had considerable impact on healthcare reforms (UNCTAD, 2004). According to GATT there are four modes of international delivery of healthcare (Outreville, 2007): 
- Cross border delivery, which includes the shipment of information and services through traditional of electronic channels (e-health or telemedicine).

- Consumption abroad, which includes the movement of patients to a foreign location. This is the classical form of medical tourism where the patient is an international traveler that seek treatment in another country.

- Commercial presence, involves the establishment of healthcare providers outside the home nation. This is a common form of foreign direct investment which can include the purchase of existing hospitals or greenfield investments where new clinics are being established abroad.

- The temporary of permanent movement of personnel, which includes mainly specialist physicians, but can even involve all kinds of hospital personnel including administrative staff. There is a growing demand for skilled hospital administrators that are moving between different countries.

To developing countries, the internationalization of healthcare can at the outset be seen as a danger of brain-drain where the best doctors are moving abroad. Due to the labour intensity of healthcare and the universal knowledge base used in the practice of medicine this is a real challenge to several countries. However, in the long run even developing countries can benefit from internationalization as personnel is returning and the number of domestically trained staff can increase over time. For a country like Mexico doctors have been moving to the US for several decades. Nowadays, American hospitals are being established in Mexico that attract US patients and provide well paid jobs to Mexican healthcare personnel.

Another source of the internationalization of medical care is the increasing investment in corporate healthcare. Large corporations who wants to provide healthcare to their employees sees the opportunities to provide some of this care abroad. There are five categories of this kind of care (Holden, 2005):

- Providers of services to end consumers which involves acute care, long-term care, home care, general clinics of specialist services as well as pharmacies, dentists and opticians.

- Producers of goods to state- of private providers. This includes drugs and medicines, medical equipment or information and communication technologies (ITC).

- Suppliers of services to both the state and private sector and this may include ancillary service, management services and consultancy.

- Private insurers. These may include traditional health insurers as well as health and maintenance organizations and pharmacy benefit organizations.

- Providers of maintenance of premises, includes real estate investment trusts which are particularly important to providers of long-term care.

All these categories are subject to various degrees of internationalization. New international actors are found in the provision of both goods and services. 
Medical tourism is particularly concerned with the internationalization of medical services. International insurers are also an integral part of the new more globalized healthcare industry. Long-term care for pensioners is a growing area where especially pensioners' demand retirement premises that include the access to appropriate medical care. Moving to a country with lower cost of care can enable a standard of medical care exceeding that which is provided in the home country.

\section{Stages in the Internationalization Process of Medical Care}

A first stage in the internationalization of healthcare is the deliberate soliciting of patients in order to attract new patients to a specific country or a specific hospital. This means that a hospital system sees it as a source of income to attract international patients. New patients that gain access to healthcare means that the critical mass of patients increases. Hospitals may be able to invest in new equipment or be able to provide more specialized care. Countries being seriously engaged in international medical tourism often engage in destination marketing in order to attract patients to specific destinations.

A second stage in the internationalization of healthcare is the signing of agreements between countries and hospital systems to take care of patients in general or specific groups of patients. The largest such agreement is that within the European Union. The EU has given its inhabitants the right to seek planned healthcare throughout the Union. This means that a patient can find treatment in all EU countries and the treatment can under certain conditions be paid by the health insurance in the home country. The EU Directive 2011/24/EU on patients' rights in cross-border healthcare provides the conditions for the rights of EU citizens to seek healthcare throughout the EU. Individual countries seeks agreements for its patients to travel abroad for care. One example of this are transplantation patients from Iceland that can seek healthcare in Sweden. Iceland is too small a country to provide its citizens with transplantation of vital organs and have agreed to pay for this treatment in Sweden.

A third and final stage of the internationalization of healthcare is the provision of an advanced support system for receiving international patients. Some countries' hospitals have put in place large organizations that arranges for the reception of international patients. This involves support throughout the hospital treatment, from the contact with potential patients throughout the care and the aftercare of the patient. Major hospitals may employ as many as one hundred employees to take care of these patients. Large hospitals in the US and in countries like Germany, Switzerland or Thailand have large organizations that organizes medical tourism for international patients. This involves anything from the marketing of destinations and hospitals to concierge services for international patients and customer relationship management. The three stages in the internationalization of healthcare are the following. 
- Stage 1: The active soliciting of international patients in order to attract new patients to specific hospitals.

- Stage 2: The signing of agreements between different countries' hospital systems to allow a flow of international patients.

- Stage 3: The building of a large organizational structure to support international patients throughout the treatment period.

Only the 30 most prominent countries in medical tourism have gone through all the three stages in the internationalization process. These are the countries that are well organized to receive international patients and are viewing international medical tourism as a source of income and see international patients as a useful addition to its domestic patients. Other countries are in different stages of internationalization. More internationalization of healthcare can assist the spread of medical innovations as hospitals are competing for the same groups of patients and face competitive pressure from hospitals internationally.

Figure 1. The Spread of Innovation through Internationalization

Degree of internationalization

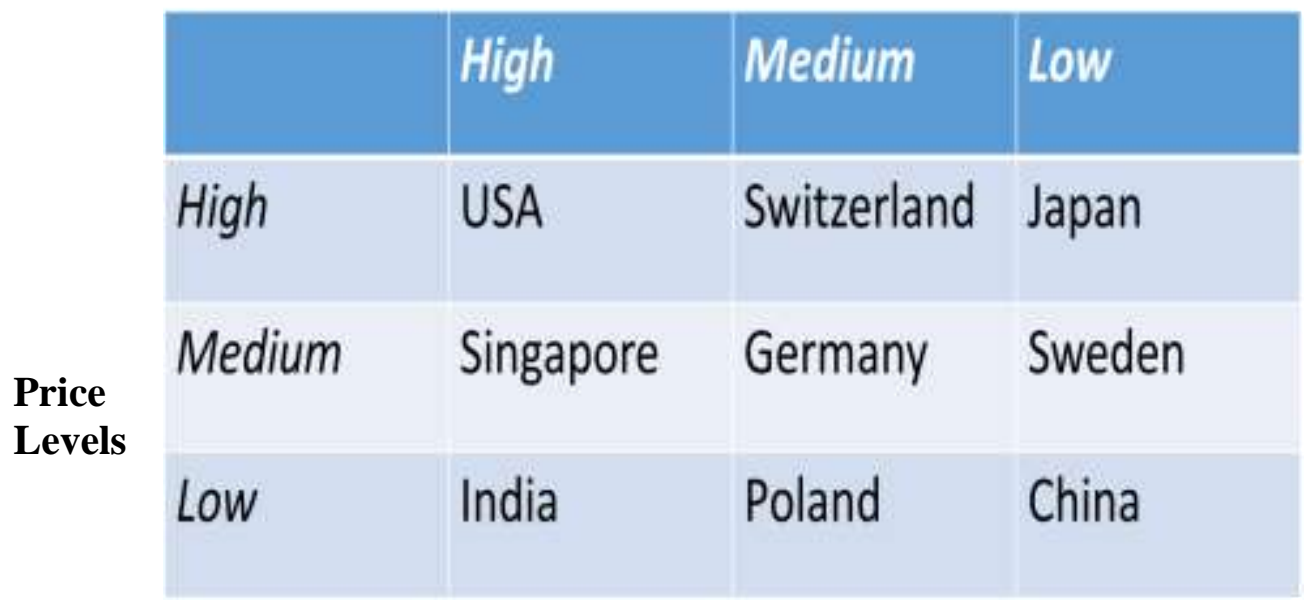

Internationalization is viewed as a means of diffusing innovation. Fruits of innovation can be captured through increased internationalization, and innovation in turn has a positive impact on corporate performance (Kafouros, 2008). This is also true within the healthcare industry. Disease is universal and is almost evenly spread internationally. Most innovation can have an immediate international impact (Carlsson, 2006). The innovators of new treatments or pharmaceuticals can gain access to an international market. Research on international innovation can be summed up with the following four points (Pavitt, 2001, 2002):

- Research and development may be less internationalized than other activities of an organization. Corporations have a tendency to keep their R\&D at home. 
- The national system of innovation is highly influential on basic research and the development of skills. Local competitive rivalry and local inducement systems influence the organizations' R\&D levels.

- Contributions to complex problem solving are person-embodied tacit knowledge. Basic research returns have more impact on local levels.

- Competitive levels are dependent on government policies and the behavior of national institutions regarding research and development.

Although research in medicine is highly international and the result of research is published internationally its impact on healthcare procedures are local. Hospitals shows different results in treatment, and the funding of medical research is often nationally based and funded by government institutions. Medical skills are embedded in the medical staff that are more or less capable of treating patients.

\section{Pricing in Medical Tourism}

Despite many people looking for the best or at least better quality of medical treatment the cost of the treatment is not a negligible factor. Connell (2006) argues that along with other factors such as long waiting lists, lower flight prices, an affluent baby-boom generation, information technology and the Internet the western countries' high costs of medical treatment has propelled the growth of medical tourism. So high treatment costs could chase patients away but when turned into prices for the treatment there are obvious positive effects for the medical care provider.

Pricing provides financial resources to clinics and hospitals thereby enabling them to keep and recruit personnel as well as providing training and courses for the personnel and possibilities to purchase new and better medical equipment and new technology. International medical tourism patients could secure a large enough patient base to maintain and develop a particular kind of treatment in the clinic, thanks to the prices they pay for their medical treatment. Thereby medical tourism contributes to have a more experienced and better trained personnel working with better equipment benefitting both domestic and foreign patients.

Three important ways to pay for the medical treatments in medical tourism are as follows:

1. The medical treatments are paid by patient insurances from insurance companies

2. Governments in other countries, having contracts with a hospital or a country providing medical treatments which are not given in the home country, pay for the treatment

3. Private patients pay out of their own pocket for the medical treatment 
In order to exploit the above mentioned benefits and to develop medical tourism there has to be a will, a vision and an open-mindedness among crucial actors in the health care system including such ones as the medical staff, entrepreneurs and politicians. Thus motivation and boldness are indispensable and a crucial question for the motivation is who will receive the money for the treatment. If the clinic providing the medical treatment - and not the authorities - receives the payment for it the motivation among the medical personnel for providing the extra medical care for international patients increases strengthening the development of medical tourism. Germany made this decision in 1998 resulting in a strong increase of the will to treat international patients (Hoefert and Hellmann, 2008). Reaping the fruits of your labor, toil and efforts is a fundamental human incentive, also valid in the healthcare industry. This is probably even more so when making new ground introducing new ways of thinking having to fight different forms of resistance to change where entrepreneurial spirit, courage and perseverance are asked for among business people along with an allowing stance and dogma-free broadmindedness on the part of authorities and politicians turning them from treatment blockers into industry enablers. So although medical tourism can open up prosperous opportunities it is still part of a larger system. Herrick (2007) argues medical tourism is but one aspect of the globalization of US healthcare system where other elements are outsourcing to skilled professionals abroad including interpretation of diagnostic tests and long-distance international collaboration. This is not unique for the United States, other countries perform and experience these phenomena as well.

Finding the prices for a particular treatment is not always so easy, particularly not regarding complex treatments where you cannot know in advance all the steps that have to be taken in the treatment process, for instance in complicated cancer treatment. In our interviews conducted in countries such as Sweden and The United States we found that particularly high-end hospitals focus on complex medical treatments often involving cooperation between specialists from various medical disciplines. Such a mastery of complex medical care can, not least in the United States, come with a hefty price tag being highly profitable for the medical care provider but being seen as acceptable by well-off patients in dire need of advanced medical treatment. That may be tertiary care or even research based quaternary care with experimental medicine or rare surgery being offered by such hospitals as the Mayo Clinic in Rochester Minnesota or Johns Hopkins Medicine in Baltimore Maryland or the New Karolinska university hospital in Stockholm, Sweden.

Coming down to concrete prices though I. Cohen (2015) refers to the USA National Center for Policy Analysis estimates of costs for common procedures for US patients at home and abroad. For a heart-valve replacement the US retail price would be 274395 USD, for US insurers the cost would be 122969 USD, in India it would be 9500 USD, in Thailand 10500 USD and in Singapore 13000 USD. This shows that the highest price is 29 times higher than the lowest price in India. For knee replacement the price differences are not as extreme by still very high where the retail price in the US would be 
69991 USD, for US insurers the cost would be 30358 , in India it would be 8500 USD in Thailand 10000 USD and in Singapore 13000 USD where the most expensive treatment is over eight times more expensive than the lowest cost alternative. These huge price differences are strong drivers for US patients seeking medical treatment in Asian countries. Another example of these huge price differences, although a few years old, comes from Connell (2006) saying an open heart surgery could cost around 150000 USD in the United States, around 70000 USD in Great Britain and only between 3000 and 10000 USD in India. So why do these huge price differences exist?

Herrick (2007) gives a number of reasons why foreign hospitals can offer much lower prices than US ones. The labor costs are much lower reducing building and operation costs, the doctors earn significantly less and for the nurses, semiskilled and unskilled labor the salary difference with the US is even bigger. Another reasons is less or no third party payment - where not the patients but the insurance companies, the employers and the government pay a significant share of the medical treatment making the patients not act as consumers but rather as persons spending others' people money being much less restrictive with what they pay for the medical care mentioning that in USA treatments not subsidized by third party actors are much more entrepreneurial and competitive. Herrick (2007) further argues there is more price transparency and package pricing in other countries so that medical travel intermediaries and patients can compare prices and this increased competition has a lowering effect on prices. According to Herrick (2007) outside of the USA there are few cross-subsidiaries where revenues from some patients cover the costs for other patients, lowering the prices for the medical treatment as only one patient has to be paid for. Another factor is streamlined services where specialty clinics and hospitals have optimized and streamlined their almost industrial medical process making it highly efficient and less expensive. Moreover there is limited malpractice liability resulting in lower insurance costs for the doctors and there are fewer cost-increasing regulations and foreign hospitals can employ physicians directly for a certain number of hours per month. All these factors contribute to much lower medical treatment prices outside of the USA.

One way to estimate overall costs for the medical treatment on average in a country could be to see how much a country spends on Medical Care as share of their GDP. Bloomberg (2016) has conducted such a study on the most efficient healthcare systems in the world including 55 countries in 2016. At the top being the country with the most efficient health system we have Hong Kong spending 2021 USD per capita and year or 5,40 \% of GDP also having the world's highest life expectancy of 83,98 years while the corresponding figures for its closest followers Singapore is 2752 USD, 4,92 \% of GDP and 82,65 years and for Spain 2658 USD, 9,03\% of GDP and 83,80 years. The USA comes at place 50 out of 55 countries with the corresponding figures spending 9403 USD per capita and year on healthcare, 17,14\% of GDP and a life expectancy of 78,94 years. Apart from the healthcare system other factors such as lifestyles, social support and inequality etc. also have an influence on the life expectancy. 
Pricing is of course a way to compete and Connell (2006) claims the Middle East is unable to compete on price and has therefore chosen to compete on quality where Dubai to guarantee high quality care has brought in German doctors and Lebanon stresses that many of their doctors are trained in Europe and America. He continues saying countries in the Caribbean have faced difficulties to enter the US market for medical tourism since they could not compete with the prices offered by Latin American countries. Herrick (2007) claims of all medical tourism destinations India arguably has the lowest prices and the best quality while Thailand having less visible poverty and better infrastructure is slightly more expensive relying on its strong tourism industry for medical tourism patients whereas the considerably richer Singapore relies on high quality hospitals being more expensive than Thailand but having much lower prices than the USA. In line with this Connell (2006) argues that prices in most Asian countries remain considerably lower than in more developed Western countries and this difference even diverges adding that India has taken a considerable share of the market thanks to significantly lower prices than other possible destinations while Singapore stressing their superior technology level has chosen to compete on quality rather than on price. To succeed this strategy requires that the patients find the higher price acceptable and worthwhile.

Thus, the perception of the price for the medical treatment and whether it is affordable, adequate, and fair or not, could be a decisive factor regarding whether a patient will accept the treatment offer or not. In a study of clinics in two metropolitan areas in South Korea Han and Hyan (2015) investigated medical tourism patients' perception of the price for medical treatment - if the product is cheap or expensive and the price reasonable or unreasonable. They used questionnaires in Chinese, English, Japanese and Korean language. They see price reasonableness as if the price of a product or service is appropriate when compared to the offers from the competitors. They add that price of a medical clinic's services include both the medical service, i.e. the pure medical treatment, and the hospitality service. Han and Hyan (2015) claim US and Japanese patients travel abroad for less expensive medical treatment prices while Chinese patients go for high quality care at reasonable prices. One third of the patients came from China, one third from Japan and one ninth from the USA. Two thirds of the patients were women. Han and Hyan (2015) found that the patients seeing the pricing as reasonable had stronger intentions to revisit the clinic and South Korea as a destination for medical treatment. In order to attract more medical tourists South Korea has focused on developing this industry where the Korean Health Industry Development Institute (KHIDI) has a crucial role as became evident in our interviews in Seoul in June 2015 and with KHIDI representatives in New York in November 2013. The South Korean commitment where industry, politics and authorities cooperate to develop the industry along with the advanced technology and equipment, treatment development and accuracy when visiting a voice clinic operating vocal chords in Seoul in June 2015 were all impressive, well in line with South Koreas strong focus on investing in education and knowledge. 
Another Asian country with a strong focus on developing medical tourism is Thailand, where the eminent Thai service culture and their strongly developed tourism industry constitute a competitive edge for them in an industry with so much human interaction as the healthcare sector. Medical tourism gives an economical contribution but it comes with a price, thus there are both upsides and downsides when developing medical tourism.

According to Anchana Naranong and Viroj NaRanong (2011) Thailand provided in 2007 medical care for 1,4 million foreign patients and they estimate that around $30 \%$ corresponding to 420000 of them were medical tourists adding that medical tourism usually seek more expensive and intensive medical treatments than other foreign patients. They argue that the value added from medical tourism is less than it seems since some of the materials such as drugs and medical equipment are imported and if these Thai doctors were not treating foreign patients some of them would treat Thai patients thereby also contributing to Thai economy and therefore these materials and some of the services have to be deducted to see the real value added of medical tourism for the Thai economy. Contributing to the value added are activities done before and after the medical treatment by medical tourism patients and the people accompany them. They claim in 2008 Thailand had revenues of about 1,5 to 1,8 billion USD on medical tourism and another 0,4 billion USD on related tourism giving a total of 1,9 to 2,2 billion USD. This gives a value added of 1,0 to 1,2 billion USD for medical services and around 0,2 USD for related tourism. Thus the value added revenues amounts to 1,2 to 1,4 billion USD corresponding to $0,4 \%$ of Thailand's GDP. Yet they see a risk that the shortage of doctors in Thailand will be aggravated by medical tourism attracting the best doctors from university teaching hospitals to private clinics and the treatment fees for middle-class Thais would increase rapidly forcing many of them to rely on the public health system and not on private clinics as they have done before and to retain doctors in the public sectors their salaries were doubled and the nurses also got higher salaries which had negative effects on Thailand's budget.

Also for a country as the United States having one of the highest healthcare costs in the world, according to Bloomberg (2016), medical tourism could be double-sided blessing. Herrick (2007) argues that global competition in healthcare could both increase and decrease the price level in the USA. The competition for patients among healthcare providers could put price pressure on hospitals but the hunt for qualified personnel could on the other hand create shortages of personnel raising the salaries for the medical staff. He claims this could be the case if foreign doctors, nurses and medical students currently working in the USA would chose to work in their home country or some other country or if foreign physicians and nurses would become less willing to come and work in the USA and the competition for qualified medical staff could also worsen the shortage of primary care physicians in the United States.

While South Korea and Thailand mainly are medical tourism destination countries one has to see the other side, a country from which many medical tourism patients come. According to Herrick (2007) in year 2005 about half a 
million US citizens sought medical treatment abroad where the majority went to Mexico and other Latin American countries but they were also among the 250000 foreign patients seeking care in Singapore, the 500000 , and the 500000 foreign patients seeking care in India and the 1 million seeking care in Thailand. As we have seen above in the case of Thailand not all of these patients could be qualified as medical tourists, since this figure includes both expatriates and persons being in the country for other reasons than seeking medical care. Thus using the Thai estimate of $30 \%$ being medical tourist brings an approximate figure of roughly 150000 US citizens being medical tourists in year 2005. Yet there are many medical tourists coming from the United States. Regarding South Koreas as a medical treatment destination Han and Hyan (2015) saw that international medical tourist find the quality of the medical treatment in a clinic more important than the quality of the service it provides. This confirms information from many of our interviews in various countries, that for patients the outcome of the medical treatment is the most important factor when travelling abroad for medical care.

Herrick (2007) concludes that as competition in the US healthcare industry will increase as more insured US patients travel abroad for low-cost medical treatment while the number of uninsured and self-paying patients traveling abroad for medical care will grow in third-party payment healthcare systems such as the one of the USA. But there are also medical tourism patients going for a more luxury environment while undergoing their medical treatment. This double-sided sword regarding the preferences of medical tourists asks for a business strategy. Thus Han and Hyan (2015) recommend a market segmentation of the medical care and related services based on detailed prices and services strategies where services with lower prices for the majority of patients from some Western countries while for upper-class individuals from both developing and developed countries higher prices would seem reasonable for superior levels of medical care and hotel style services and luxury hospital buildings. In July 2014 and related to a research interview we conducted we visited one such lavish hospitel - a kind of five-star Hotel Hospital - Mount Elizabeth Novena in Singapore with impressively luxury suits and patient rooms.

\section{Degrees of Internationalization and Price differences between Countries}

Contemplating the figure 1 shown before and in line with the discussion above we find that among countries with a high degree of internationalisation such as the United States, having had a pioneering role in international medical tourism for affluent people demanding advanced medical treatment, as well as Singapore and India, and Thailand too for that matter, could be grouped into three price level categories where the United States have a high price level while Thailand and especially India offer medical treatment for a much lower price and Singapore although laying closer to their Asian neigbour Thailand than the United States in terms of prices still may be considered to have a medium price level. Singapore stresses their advanced technology and 
internationally trained doctors having worked for some years in North America or Europe, particularly in the United States or Great Brittan, as became evident in our interviews in Singapore in July 2014.

Regarding countries with a medium degree of internationalization and also considering their reltive cost level in their home continent we see that Switzerland has high costs whereas the cost level in Poland is much lower competing on price while Germany comes in between but being clearly more expensive than Poland. Yet Poland has many newly built and modern clinics and hospitals as our various interviews and hospital visits in Warsaw and other Polish locations in December 2014 and April 2017 showed while Germany has successfully put much effort into developing their medical tourism industry as our cooperation with leading German researchers in the field and our interviews and research conversations on site have shown.

In the group of countries which have not such a high degree of internationalization we find Japan which is a very fascinating country where we conducted several interviews and research visits at hospitals. Japan features highly advanced healthcare with advanced methods and equipment but it is rather expensive, not least in comparison to its Asian neighbors. The base for our research, Sweden, where we have conducted many interviews and visited many hospitals, has not developed medical tourism so much and the price level is also at a medium stage. China has undergone a fantastic economic development during almost forty years becoming the export leader of the world but they have not yet internationalized their medical sector to the same degree as some of their Asian neighbors earlier mentioned here and their price level is not so high either.

\section{Concluding Remarks}

Medical tourism is one of the fastest growing global industries. It represents a promising combination of healthcare and tourism. The 30 countries that are strongly engaged in this field enjoy income from both increased tourism and from revenue generated at their hospitals. The tourism aspect of the healthcare experience can be seen to improve the perceived quality of care and can take the negative tension away from the treatment. Some patient groups spend on average only $30 \%$ of their time during treatment at the hospital. The rest of the time is generally free to pursue other interests. Hospitals that can offer patients and their relatives alternative activities become more attractive care destinations. Being physically active automatically brings health benefits. Sickness has negative connotation while tourism is seen as something positive. Combining healthcare with tourism can remove part of the burden of being sick.

Different countries and hospitals are more or less prepared to receive international patients. They are on different stages in their internationalization process. Only a limited number of hospitals have built up an infrastructure that takes into considerations all the patients' needs and desires. This requires a 
large number of auxiliary staff that communicates with the presumptive patients, preferably in their native language and stays in touch with the patients during and after the treatment. Staff should also be able to communicate with tourism operators that offer the patients transportation, accommodation and entertainment.

Different countries have different conditions and possibilities to compete in the global market for healthcare. Some countries such as the United States, Switzerland and Japan have high healthcare cost and receive the wealthier patients. At the other end are countries like India, China and Poland having low or very low production cost for medical treatment thus competing for patients with lower income. In the middle is a range of countries including Germany, Singapore and Sweden that can compete with more affordable, but not the cheapest, prices of healthcare.

Major differences in price for medical treatment propel medical tourism patients from Western countries, not least uninsured or not sufficiently insured US citizens, to seek medical treatment in Asian and Latin American countries, There those patients are given good quality but much more affordable medical care than in their home country.

\section{Acknowledgements}

We would like to thank the more than 80 interviewees that have been interviewed by us on site in Asia, Europe and North America or during conferences in the US and in Sweden. Our thanks also go to our financiers the Knowledge foundation and the Söderberg foundation in Sweden.

\section{References}

Bark C (2011) Direktivet som förändrar vården i Europa. (The Directive that changes health care in Europe), Sjukhusläkaren. Stockholm.

Beyer I, Juszczak J (2014) Ergebnisse der 6. Marktstudie "Internationale Patienten in deutschen Kliniken" (International Patients in German clinics). In: Juszczak J and Ebel B (eds.) Einwerbung und Betreuung internationaler Patienten. Tagungsband zur 4 Konferenz Medizintourismus Sankt Augustin 12. September 2013 (Attracting and guiding international patients, Proceedings of the fourth conference on medical tourism, St Augustin September 2013). Sankt Augustin: Schriftenreihe des Fachbereichs Wirtschaft der Fachhochschule Bonn-RheinSieg, Band 34: 27-44.

Białk-Wolf A (2010) Potencjal rozwojowi turystiki medycznej (Potentials for the development of medical tourism). In: Zeszyty Naukowe Universytetu Szczecinskiego, Ekonomiczne Problemy Uslug, 591: 653-662.

Białk-Wolf A. (2014) Turystyka medyczna. Perspektywy rozwoju w woj. Pomorskim (Medical Tourism. Potentials for the development in the province of Pomerania). Gdansk, p. 8. http://www.gdansk4u.pl/uploads/TurystykaMedycznaRaport.pdf.

Bloomberg (2016) U.S. Health-Care System Ranks as One of the Least-Efficient; America is number 50 out of 55 countries that were assessed. Available at: 
https://www.bloomberg.com/news/articles/2016-09-29/u-s-health-care-system-ra nks-as-one-of-the-least-efficient

Bookman MZ and Bookman KR (2007) Medical Tourism in Developing Countries. New York: Palgrave Macmillan.

Borg EA and Ljungbo K (2017) Ganzheitliche und avancierte, doch teure medizinische Dienstleistungen. Beobachtungen in renommierten US-amerikanischen Krankenhäusern (Comprehensive and advanced but expensive medical services. Observations in highly ranked US hospitals). In: Kirsch FM and Juszczak J (eds.) Medizintourismus. Erfahrungen mit einer weltweiten Wachstumsbranche (Medical Tourism. Experiences with a global growth industry). Paderborn: IFB Verlag Deutsche Sprache, 213-250.

Burkett L (2007) Medical Tourism. Concerns, Benefits, and the American Legal Perspective. The Journal of Legal Medicine 28(2): 223-245.

Carlsson B (2006) Internationalization of innovation systems: A survey of the literature. Research Policy 35: 56-67.

CHAFEA (2014) The Executive Agency for Consumers, Health and Food. Impact of information on patients' choice within the context of the Directive 2011/24/EU of the European Parliament and of the Council on the application of patients' rights in cross-border healthcare. Final Report. London: Ipsos and London Economics.

Cohen IG (2015) Patients with Passports. Medical Tourism, Law, and Ethics. New York: Oxford University Press.

Connell J (2006) Sea, sun, sand and surgery. Tourism Management 27: 1093-1100.

Ehrbeck T, Guevara C, and Mango PD (2008) Mapping the market for medical travel. The McKinsey Quarterly. Health Care 1-11.

European Commission (2015) Special Eurobarometer 425 "Patient's rights in crossborder health care in the European Union". Report, conducted by TNS Opinion and Social at the request of the European Commission, Directorate-General for Health and Consumers (SANCO).

Glinos IA, Baeten R, and Maarse H (2010) Purchasing health services abroad: Practices of cross-border contracting and patient mobility in six European countries. Health Policy 95(2): 103-112.

Grant C (2014) Johns Hopkins Medicine International, Baltimore, USA, Interview 24.9.2014.

Hall CM (2011) Health and medical tourism: a kill or cure for global public health? Tourism Review 66: 4-15.

Han H and Hyan SS (2015) Customer retention in the medical tourism industry: Impact of quality, satisfaction, trust and price reasonableness. Tourism Management 46: $20-29$.

Herrick DM (2007) Medical tourism: Global competition in health care, NCPA Policy Report No. 304. National Center for Policy Analysis. ISBN \#1-56808-178-2.

Heung VCS, Kucusta D, and Song H (2010) A Conceptual Model of Medical Tourism: Implications for Future Research. Journal of Travel and Tourism Marketing 27(3): 236-251.

Heuwinkel K (2009) Health Tour Mobil-Ansatz zur Etablierung eines branchenübergreifenden Medizintourismus (Health tour mobility method, establishing a branch covered medical tourism). In: Juszczak J and Ebel B (eds.) Einwerbung und Betreuung internationaler Patienten. Tagungsband zur 2. Konferenz Medizintourismus Sankt Augustin 16./17. September 2009 (Attracting and guiding international patients, Proceedings of the second conference on medical tourism, St Augustin September 2009). Schriftenreihe des Fachbereichs Wirtschaftswissenschaften, 28: 100-108. 
Hoefert HW and Hellmann W (2008) Kommunikation als Erfolgsfaktor im Krankenhaus (Communication as a success factor in hospitals). Heidelberg: medhochzwei Verlag.

Holden C (2003) Actors and motives in the internationalization of the health businesses, Business and Politics 5(3): 287-302.

Holden C (2015) The internationalization of corporate healthcare: extent and emerging trends. Competition \& Change 9(2): 201-219.

Horowitz MD and Rosensweig JA (2007) Medical Tourism - Health Care in the Global Economy. Physician Executive 33(6): 24-30.

Johnston R, Crooks VA, Snyder J, and Kingsbury P (2010) What is known about the effects of medical tourism in destination and departure countries? A scoping review. International Journal for Equity in Health 9: 24.

Juszczak J (2017) Russische Patienten in deutschen Kliniken. Erfahrungen und Herausforderungen (Russian patients in German clinics. Experiences and challenges). In: Kirsch FM and Juszczak J (eds.) Medizintourismus. Erfahrungen mit einer weltweiten Wachstumsbranche (Medical Tourism. Experiences with a global growth industry). Paderborn: IFB Verlag Deutsche Sprache, 36-70.

Kangas B (2010) Traveling for Medical Care in a Global World. Medical Anthropology: Cross- Cultural Studies in Health and Illness, 29(4): 344-362.

Kafouros MI, Buckley PJ, Sharp JA, and Wang C (2008) The role of internationalization in explaining innovation performance. Technovation 28: 63-74.

Kirsch FM and Białk-Wolf A (2016) Medizintourismus aus deutscher Sicht. Interview mit deutschem Experten (Medical tourism from a German perspective. Interview with a German expert). Available at: http://bit.ly/2qVgdeW.

Kirsch FM (2015) Chance, Muss oder Spaltpilz? Medizintourismus in Deutschland und Schweden (Opportunity, compulsary or devisive? Medical tourism in Germany and Sweden). In: Becker C and Grub FT (eds.) Perspektive Nord: Zu Theorie und Praxis einer modernen Didaktik der Landeskunde. Beiträge zur 2. Konferenz des Netzwerks Landeskunde Nord in Stockholm am 24./25. Januar 2014 (Perspective North: On theory and practice of a modern didactic in regional studies). Frankfurt am Main: Peter Lang, 133-154.

Kirsch FM (2017) Verschenkte Chancen? Schweden und der Medizintourismus (Lost opportunities? Sweden and the medical tourism). In Kirsch FM and Juszczak J (eds.) Medizintourismus. Erfahrungen mit einer weltweiten Wachstumsbranche. Paderborn: IFB Verlag Deutsche Sprache, 329-363.

Kuhlmann E and Burau V (2008) The 'healthcare state' in transition, national and international contexts of changing professional governance. European Societies 10(4): 619-633.

Legido-Quigley H and McKee M (2010) Patients seeking treatment abroad: Another challenge for general practice commissioning. British Medical Journal, 341: 845846.

Mason A and Wright KB (2010) Framing Medical Tourism. Journal of Health Communication: International Perspectives 16(2): 163-177.

NaRanong A and NaRanong V (2011) The effects of medical tourism: Thailand's experience. Bull World Health Organ 89: 336-344.

Outreville JF (1998) The health insurance sector: market segmentation and international trade in health services. In: UNCTAD (eds.) International trade in health services: a development perspective. Geneva: United Nations.

Outreville JF (2007) Foreign direct investment in the health care sector and mostfavoured locations in developing countries. European Journal of Health Economics 8: 305-312. 
Pavitt K (2001) Managing global innovation: uncovering the secrets of future competitiveness. Research Policy 30(1): 176-177.

Pavitt K (2002) The globalizing learning economy. Academy of Management Review 27(1): 125-127.

Rogers BA, Aminzadeh Z, Hayashi Y, and Paterson D (2011) Country-to-Country Transfer of Patients and the Risk of Multi-Resistant Bacterial Infection. Clinical Infections Diseases. Oxford University Press, 53: 49-56.

Smith RD (2004) Foreign direct investment and trade in health-services: a review of the literature. Social Science \& Medicine 59: 2313-2323.

Sobo EJ (2009) Medical Travel: What it Means, Why it Matters. Medical Anthropology: Cross-Cultural Studies in Health and Illness. London: Routledge, 28: 326-335.

2011/24/EU (2015) Commission report on the operation of Directive 2011/24/EU on the application of patients' rights in cross-border healthcare. Brussels, 2015-0904.

UNCTAD (2004) World Investment Report 2004, The shift towards service. Geneva: United Nations.

Underwood HR and Makadon HJ (2010) Medical tourism: Game Changing Innovation or Passing Fad? Journal of the Healthcare Financial Management Association 64(9): 112-118.

Von Lutterotti N (2010) Die Kranken von weit her (The patients from far away). Frankfurter Allgemeine Zeitung. Frankfurt am Main.

Whittaker A (2008) Pleasure and pain: Medical travel in Asia. Global Public Health 3: 271-290. 
